\title{
哬D

8-8-2019

\section{Predicting the Effects of Supplemental EPA and DHA on the Omega-3 Index}

\author{
Rachel E. Walker \\ Kristina Harris Jackson \\ Nathan L. Tintle \\ Dordt University, nathan.tintle@dordt.edu \\ Gregory C. Shearer \\ Aldo Bernasconi
}

See next page for additional authors

Follow this and additional works at: https://digitalcollections.dordt.edu/faculty_work

Part of the Dietetics and Clinical Nutrition Commons

\section{Recommended Citation}

Walker, R. E., Jackson, K. H., Tintle, N. L., Shearer, G. C., Bernasconi, A., Masson, S., Latini, R., Heydari, B., Kwong, R. Y., Flock, M., Kris-Etherton, P. M., Hedengran, A., Carney, R. M., Skulas-Ray, A., Gidding, S. S., Dewell, A., Gardner, C. D., Grenon, M., Sarter, B., Newman, J. W., Pedersen, T. L., Larson, M. K., \& Harris, W. S. (2019). Predicting the Effects of Supplemental EPA and DHA on the Omega-3 Index. American Journal of Clinical Nutrition, 110 (4), 1034. https://doi.org/10.1093/ajcn/nqz161

This Article is brought to you for free and open access by Dordt Digital Collections. It has been accepted for inclusion in Faculty Work Comprehensive List by an authorized administrator of Dordt Digital Collections. For more information, please contact ingrid.mulder@dordt.edu. 


\title{
Predicting the Effects of Supplemental EPA and DHA on the Omega-3 Index
}

\author{
Abstract \\ Background: Supplemental long-chain omega-3 $(n-3)$ fatty acids (EPA and DHA) raise erythrocyte EPA + \\ DHA [omega-3 index (O3I)] concentrations, but the magnitude or variability of this effect is unclear. \\ Objective: The purpose of this study was to model the effects of supplemental EPA + DHA on the 03I. \\ Methods: Deidentified data from 1422 individuals from 14 published $n-3$ intervention trials were included. \\ Variables considered included dose, baseline O3I, sex, age, weight, height, chemical form [ethyl ester (EE) \\ compared with triglyceride (TG)], and duration of treatment. The O3I was measured by the same method \\ in all included studies. Variables were selected by stepwise regression using the Bayesian information \\ criterion.
}

Results: Individuals supplemented with EPA + DHA $(n=846)$ took a mean \pm SD of $1983 \pm 1297 \mathrm{mg} / \mathrm{d}$, and the placebo controls $(n=576)$ took none. The mean duration of supplementation was $13.6 \pm 6.0 \mathrm{wk}$. The O3I increased from $4.9 \% \pm 1.7 \%$ to $8.1 \% \pm 2.7 \%$ in the supplemented individuals $(P<0.0001)$. The final model included dose, baseline $03 \mathrm{I}$, and chemical formulation type (EE or TG), and these explained $62 \%$ of the variance in response $(P<0.0001)$. The model predicted that the final $03 \mathrm{I}$ (and $95 \% \mathrm{Cl})$ for a population like this, with a baseline concentration of $4.9 \%$, given $850 \mathrm{mg} / \mathrm{d}$ of EPA + DHA EE would be $\sim 6.5 \%(95 \% \mathrm{Cl}$ : $6.3 \%, 6.7 \%$ ). Gram for gram, TG-based supplements increased the $03 \mathrm{I}$ by about 1 percentage point more than EE products.

Conclusions: Of the factors tested, only baseline $03 \mathrm{l}$, dose, and chemical formulation were significant predictors of $\mathrm{O} 3 \mathrm{I}$ response to supplementation. The model developed here can be used by researchers to help estimate the $03 \mathrm{I}$ response to a given EPA + DHA dose and chemical form.

\section{Keywords}

n-3 fatty acids, omega-3 index, dietary supplements, EPA, DHA, statistical models

\section{Disciplines}

Dietetics and Clinical Nutrition

\section{Authors}

Rachel E. Walker, Kristina Harris Jackson, Nathan L. Tintle, Gregory C. Shearer, Aldo Bernasconi, Serge Masson, Roberto Latini, Bobak Heydari, Raymond Y. Kwong, Michael Flock, Penny M. Kris-Etherton, Anne Hedengran, Robert M. Carney, Ann Skulas-Ray, Samuel S. Gidding, Antonella Dewell, Christopher D. Gardner, Marlene Grenon, Barbara Sarter, John W. Newman, Theresa L. Pedersen, Mark K. Larson, and William S. Harris 


\title{
Predicting the effects of supplemental EPA and DHA on the omega-3 index
}

\author{
Rachel E Walker, ${ }^{1}$ Kristina Harris Jackson, ${ }^{2}$ Nathan L Tintle, ${ }^{3}$ Gregory C Shearer,${ }^{1,4}$ Aldo Bernasconi, ${ }^{5}$ Serge Masson, ${ }^{6}$ \\ Roberto Latini, ${ }^{6}$ Bobak Heydari, ${ }^{7}$ Raymond Y Kwong, ${ }^{8}$ Michael Flock, ${ }^{9}$ Penny M Kris-Etherton, ${ }^{1}$ Anne Hedengran, ${ }^{10}$ \\ Robert M Carney, ${ }^{11}$ Ann Skulas-Ray, ${ }^{12}$ Samuel S Gidding, ${ }^{13}$ Antonella Dewell, ${ }^{14}$ Christopher D Gardner, ${ }^{14}$ \\ $S$ Marlene Grenon, ${ }^{15}$ Barbara Sarter, ${ }^{16}$ John W Newman, ${ }^{17}$ Theresa L Pedersen, ${ }^{18}$ Mark K Larson, ${ }^{19}$ and William $S$ Harris ${ }^{2,4}$
}

${ }^{1}$ Department of Nutritional Sciences, The Pennsylvania State University, University Park, PA, USA; ${ }^{2}$ OmegaQuant Analytics, LLC, Sioux Falls, SD, USA;
${ }^{3}$ Department of Mathematics and Statistics, Dordt College, Sioux Center, IA, USA; ${ }^{4}$ Department of Internal Medicine, Sanford School of Medicine, University
of South Dakota, Sioux Falls, SD, USA; ${ }^{5}$ Global Organization for EPA and DHA, Salt Lake City, UT, USA; ${ }^{6}$ Department of Cardiovascular Research,
Institute of Pharmacological Research "Mario Negri," Milan, Italy; ${ }^{7}$ Libin Cardiovascular Institute of Alberta, University of Calgary, Calgary, Alberta,
Canada; ${ }^{8}$ Department of Medicine, Brigham and Women's Hospital, Boston, MA, USA; ${ }^{9}$ Clinical and Translational Science Institute, University of Pittsburgh,
Pittsburgh, PA, USA; ${ }^{10}$ Department of Ophthalmology, Rigshospitalet, Glostrup, Denmark; ${ }^{11}$ Department of Psychiatry, Washington University School of
Medicine, St. Louis, MO, USA; ${ }^{12}$ Department of Nutritional Sciences, University of Arizona, Tucson, AZ, USA; ${ }^{13}$ Familial Hypercholesterolemia Foundation,
Pasadena, CA, USA; ${ }^{14}$ Stanford Prevention Research Center, Stanford University, Stanford, CA, USA; ${ }^{15}$ Department of Surgery, University of California, San
Francisco, San Francisco, CA, USA; ${ }^{16}$ Department of Naturopathic Medicine, Bastyr University, San Diego, CA, USA; ${ }^{17}$ Obesity and Metabolism Research
Unit, Western Human Nutrition Research Center, Agricultural Research Service, US Department of Agriculture, Davis, CA, USA; ${ }^{18}$ Department of Food
Science and Technology, University of California, Davis, Davis, CA, USA; and ${ }^{19}$ Department of Biology, Augustana University, Sioux Falls, SD, USA

\section{ABSTRACT}

Background: Supplemental long-chain omega-3 (n-3) fatty acids (EPA and DHA) raise erythrocyte EPA + DHA [omega-3 index (O3I)] concentrations, but the magnitude or variability of this effect is unclear.

Objective: The purpose of this study was to model the effects of supplemental EPA + DHA on the O3I.

Methods: Deidentified data from 1422 individuals from 14 published $n-3$ intervention trials were included. Variables considered included dose, baseline O3I, sex, age, weight, height, chemical form [ethyl ester (EE) compared with triglyceride (TG)], and duration of treatment. The O3I was measured by the same method in all included studies. Variables were selected by stepwise regression using the Bayesian information criterion.

Results: Individuals supplemented with EPA + DHA $(n=846)$ took a mean \pm SD of $1983 \pm 1297 \mathrm{mg} / \mathrm{d}$, and the placebo controls $(n=576)$ took none. The mean duration of supplementation was $13.6 \pm 6.0$ wk. The O3I increased from $4.9 \% \pm 1.7 \%$ to $8.1 \% \pm 2.7 \%$ in the supplemented individuals $(P<0.0001)$. The final model included dose, baseline O3I, and chemical formulation type (EE or TG), and these explained $62 \%$ of the variance in response $(P<0.0001)$. The model predicted that the final O3I (and $95 \%$ CI) for a population like this, with a baseline concentration of $4.9 \%$, given $850 \mathrm{mg} / \mathrm{d}$ of EPA + DHA EE would be $\sim 6.5 \%$ (95\% CI: $6.3 \%$, $6.7 \%$ ). Gram for gram, TG-based supplements increased the O3I by about 1 percentage point more than EE products.

Conclusions: Of the factors tested, only baseline O3I, dose, and chemical formulation were significant predictors of O3I response to supplementation. The model developed here can be used by researchers to help estimate the O3I response to a given EPA + DHA dose and chemical form. Am J Clin Nutr 2019;110:1034-1040.

Keywords: n-3 fatty acids, omega-3 index, dietary supplements, EPA, DHA, statistical models

\section{Introduction}

The literature supporting the benefits of long-chain omega3 (n-3) fatty acids (LC n-3 FAs; i.e., EPA and DHA) in cardiovascular disease (CVD) has been mixed (1). A 2018 metaanalysis concluded that the current evidence did not support a

This report was self-funded by OmegaQuant Analytics, LLC, a commercial laboratory providing fatty acid analytical services for researchers, health care providers, and consumers.

Supplemental Tables 1 and 2 and Supplemental Materials are available from the "Supplementary data" link in the online posting of the article and from the same link in the online table of contents at https://academic.oup. com/ajcn/.

Address correspondence to WSH (e-mail: bill@omegaquant.com).

Abbreviations used: BIC, Bayesian information criterion; CHD, coronary heart disease; CVD, cardiovascular disease; EE, ethyl ester; FA, fatty acid; LC n-3 FA, long-chain n-3 fatty acid; O3I, omega-3 index; RCT, randomized controlled trial; TG, triglyceride.

Received January 25, 2019. Accepted for publication June 27, 2019.

First published online August 8, 2019; doi: https://doi.org/10.1093/ajcn/ nqz161. 
role for $\mathrm{n}-3$ fatty acids (FAs) in CVD risk reduction (2), but in 3 major randomized trials reported in late 2018, n-3 FA treatment significantly reduced risk for vascular death (3), myocardial infarction (4), and major adverse cardiovascular events (5). The latter study was particularly compelling as it used $4 \mathrm{~g}$ EPA (as opposed to the usual $0.84 \mathrm{~g}$ EPA + DHA) in statin-treated patients and found a $25 \%$ risk reduction in CVD events. Hence, some recent data support a role for $\mathrm{n}-3$ FAs in reducing risk for CVD.

One LC n-3 FA-based marker for which target concentrations have been proposed is the erythrocyte membrane EPA + DHA content [hereafter the omega-3 index (O3I)] (6). The O3I is EPA+DHA expressed as a weight percentage of total FAs. It has been shown to be a stable biomarker of dietary intake and a valid surrogate of tissue LC n-3 FAs (7). However, there is still large interperson variability in tissue incorporation as it relates to intake (8). The O3I was first proposed as a potential risk factor for coronary heart disease (CHD) death in 2004 (6), and subsequent cross-sectional as well as prospective studies have supported its clinical utility for that purpose (9, 10). Analysis of these studies shows that an O3I of $8 \%$ or more is protective against fatal CHD (11). The O3I is also inversely correlated with major depressive disorders and inflammatory biomarkers $(12,13)$.

Currently, there are no guidelines to help researchers determine the LC n-3 FA dose needed to attain a specific O3I or to guide clinicians in recommending LC n-3 FA doses for individual patients. Several factors are known to alter an individual's O3I response to dose, the most important of which, after the dose itself, appear to be body weight and baseline O3I $(14,15)$. Other potential factors that could affect response to dose are sex (14, $16)$, age $(14,17)$, the chemical formulation of EPA and DHA (18, 19), genetic factors (20), smoking (21), dietary fat content of the accompanying meal $(22,23)$, and possibly even choline intake (24).

In a prior, single-center study, Flock et al. (14) developed equations describing the dose-response relationship between supplemental EPA + DHA and the O3I. In the present study, we used individual-level data from Flock et al. (14) and 13 other intervention studies in which the O3I was measured pre- and postdosing to determine which factors affect the response of the O3I to supplementation with LC n-3 FAs. Using basic demographic data along with baseline O3I values, we set out to build a regression model to predict O3I responses to dose.

\section{Methods}

\section{Sample}

Data from 1422 individuals from 14 published intervention studies $(14,16,25-36)$ in which EPA + DHA dietary supplements or prescription products were given were used to predict changes in the O3I (Table 1). All investigators provided data on EPA and DHA dose, duration of supplementation, pre- and post-O3I (both determined using the same laboratory method) values from both placebo-treated and LC n-3 FA-treated subjects, and standard demographic factors. Individual study sample sizes ranged from 10 to 453 , and a variety of participant types was included. All studies were approved by local human subjects research committees, and details can be found in each cited publication.

\section{Statistical analysis}

We used paired $t$ tests to compare the effects of treatment on the O3I from baseline to end of treatment. Mixed-effects models were used to predict changes in concentrations adjusting for age, sex, race, BMI, and weight, and a random-effects term for each study was fit separately for individuals taking supplements compared with placebo. A significance level of 0.05 was used for these analyses. All statistical analyses were performed in R, version 3.5 (www.r-project.org).

To build a predictive model, we used the stepwise Bayesian information criterion (BIC) to identify the best-fitting and most parsimonious model (38). We considered 8 predictor variables for absolute change in the O3I: EPA + DHA dose (in mg/d, including both linear and quadratic terms), baseline O3I (including both linear and quadratic terms), sex, age, BMI (including both linear and quadratic terms), race (Asian, black, Hispanic, other, white), duration of treatment (weeks, including both linear and quadratic terms), and type of chemical formulation [ethyl ester (EE) or triglyceride (TG)]. We also considered 3 potential statistical interaction terms: baseline $\mathrm{O} 3 \mathrm{I}$ and dose, dose and duration, and formulation type and dose. Other factors that are known to affect the O3I, such as whether the product was taken with a meal or not (23), were not collected in these studies.

We performed the stepwise BIC approach in conjunction with a 10 -fold cross-validation. Specifically, we randomly broke the entire data set into 10 equally sized, mutually exclusive subsets, each containing $\sim 90 \%$ of the data $(n \approx 1280$; the discovery data sets). Each discovery data set then corresponded directly to a validation data set (i.e., the remaining $10 \%$ of the data, $n \approx 142$ each). The stepwise BIC model-fitting approach was performed on each of the 10 discovery data sets and validated on the corresponding validation data set. The consensus final model predictor variables and associated $\beta$ estimates were obtained by averaging across the estimates from the 10 validation data sets. $R^{2}$ was used to evaluate overall model predictive ability. Furthermore, the unique contribution of each term in the model to the overall $R^{2}$ was evaluated by looking at change in $R^{2}$ resulting from adding the term to the model.

\section{Results}

\section{Subject characteristics and overall change in the O3I}

The average age, body weight, and BMI of the participants was 56 years, $83 \mathrm{~kg}$, and $28 \mathrm{~kg} / \mathrm{m}^{2}$, respectively (Table 1). The cohort was $74 \%$ male and $91 \%$ white. Treatment groups took a mean of $1983 \mathrm{mg} / \mathrm{d}$ supplemental EPA + DHA (range: 254$4400 \mathrm{mg} / \mathrm{d}$ ), and placebo groups took $0 \mathrm{mg} / \mathrm{d}$ for a mean of $13.6 \pm 6.0 \mathrm{wk}$ (range: 4-24 wk). Compliance was reported in 7 of the 14 studies and averaged 95\%. The O3I increased from $4.9 \% \pm 1.7 \%$ to $8.1 \% \pm 2.7 \%$ in the supplemented individuals ( $n=846 ; P<0.0001$; a $65 \%$ increase) and remained unchanged in the placebo groups (from $5.0 \% \pm 1.7 \%$ to $5.1 \% \pm 1.7 \%$; $n=576 ; P=0.20$ ). 
Walker et al.

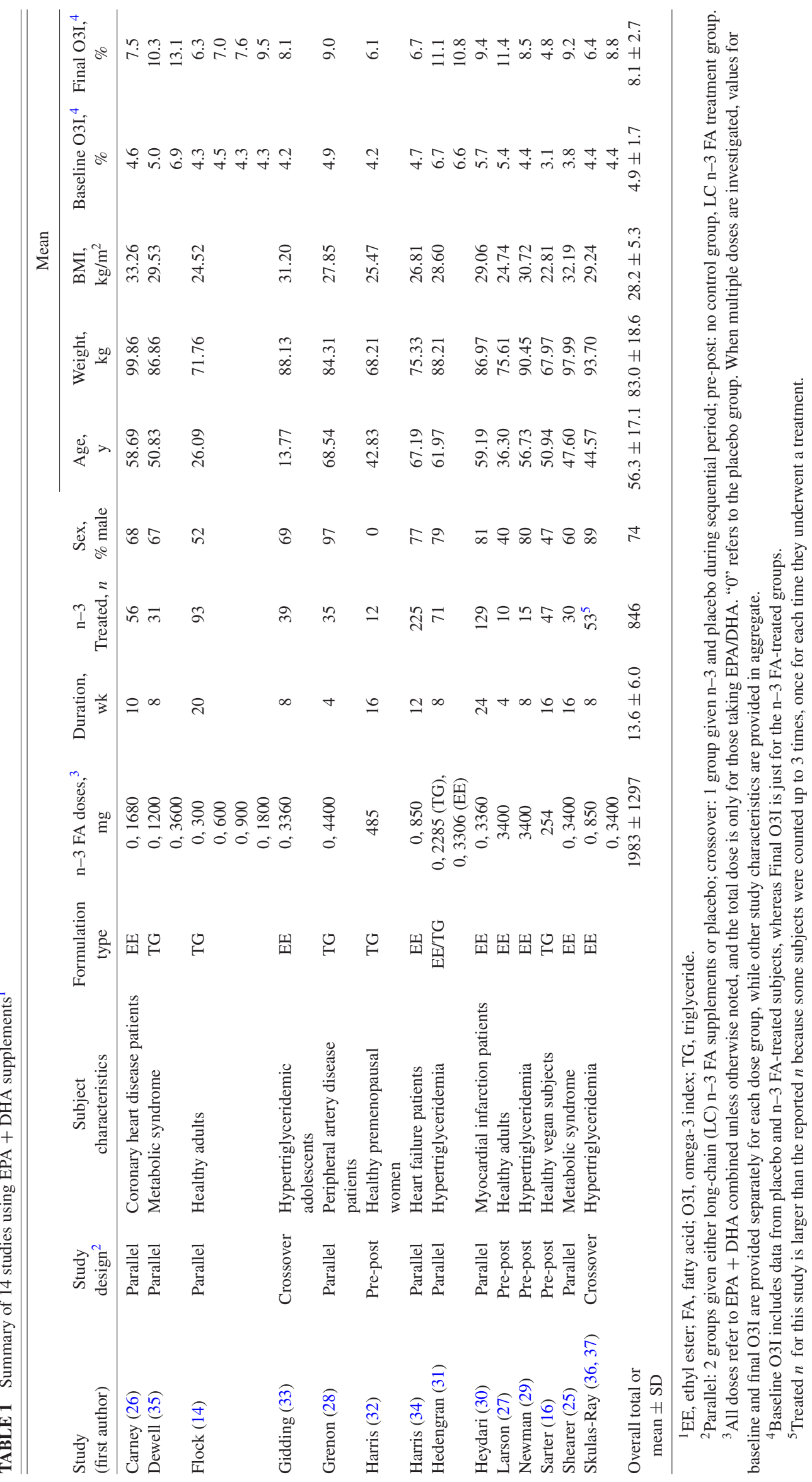


TABLE 2 Statistical model summary ${ }^{1}$

\begin{tabular}{ll}
\hline \hline Characteristic & Value \\
\hline Average $R^{2}(\mathrm{SD})$ : discovery samples (10 samples of $n=1280$ each) & $0.59(0.006)$ \\
Average $R^{2}(\mathrm{SD})$ : validation samples $(10$ samples of $n=142$ each) & $0.62(0.05)$ \\
Variables included and significant in validation sample (unique $\left.R^{2}\right)^{2}$ & $\bullet$ Baseline O3I (quadratic) $(0.04)$ \\
& $\bullet$ Dose (mg/d) (quadratic) $(0.16)^{3}$ \\
& $\bullet$ Type $(0.01)$ \\
Model equation from validation samples & Change in O3I $=2.60+0.921 * \mathrm{TG}-0.842 *$ Baseline O3I \\
& $+0.050 *$ Baseline O3I $^{2}+0.0027$ Dose \\
& $-\left(4.1 \times 10^{-7}\right)_{\text {Dose }^{2}}$
\end{tabular}

\footnotetext{
${ }^{1} \mathrm{O} 3 \mathrm{I}$, omega-3 index; TG, triglyceride.

${ }^{2}$ Unique $R^{2}$ is calculated as the change in model $R^{2}$ obtained when dropping the term but keeping all other terms in the model.

${ }^{3}$ There is high covariation between dose and type because the type variable has 3 groups [placebo, ethyl ester (EE), and TG], and so Dose $=0$ is the same as the placebo group. Baseline O3I values are entered as full integer, not as fraction or percentage. Dose is entered as mg/d. For type, enter "1" for TG forms and " 0 " for EE forms. O3I = RBC EPA + DHA as a percentage of total fatty acids.

${ }^{4}$ The SDs of the 6 model coefficients across the 10 validation samples are $0.40,0.17,0.012,0.12,0.0004$, and $9 \times 10^{-8}$, respectively.
}

\section{Modeling the O3I response to treatment}

After development and validation following the 10-fold crossvalidation approach, the model included baseline O3I and $\mathrm{EPA}+\mathrm{DHA}$ dose, including quadratic terms for both variables, and the chemical form (type) of EPA + DHA. This model explained $62 \%$ of the variance. By comparing the $R^{2}$ values with and without each variable, we found that dose was uniquely responsible for $80 \%$ of the explanatory ability $\left(R^{2}\right)$ followed by baseline O3I (15\%) and type of supplement $(5 \%)$. Explained variation was similar for discovery samples and validation samples. Model coefficients, terms, and $R^{2}$ (overall and unique contribution) values are in Table 2 , with additional details on the model-building and cross-validation process in Supplemental Tables 1 and 2 .

The predicted change in the O3I (adjusted using the model) was significantly higher for TG compared with EE forms (mean, $+0.89 \%$; $95 \%$ CI: $0.63 \%, 1.15 \%$ ). The equation was rearranged to estimate the dose (separately for EE and TG forms) necessary to attain an O3I of 8\% as a function of the baseline O3I (Figure 1; see Supplemental Materials, Results). To confirm that this model would also perform well for predicting the final O3I, we compared the predicted with the observed final O3I values (Figure 2). Observed values correlated with predicted values, with an $R^{2}$ of 0.69 . To evaluate model robustness, we considered 1) weight ( $\mathrm{kg}$ ) instead of BMI, 2) dose $/ \mathrm{kg}$ body weight instead of dose, and 3) the ratio of EPA to DHA in the supplement. In all cases, there was little effect on the final model (details not shown).

\section{Discussion}

In this report, we developed a model to predict the effects of LC n-3 FA supplementation on the O3I. The model had a relatively high $R^{2}$ value in both discovery and validation samples, as well as between observed and predicted O3I values. In order of importance, the major determinants of the O3I response were dose, the baseline O3I, and type of supplement. The response was not linear; therefore, some polynomial terms were needed to best predict the response.

In addition to dose and the baseline O3I, which have been previously reported to influence the O3I response to EPA + DHA treatment $(14,15)$, supplement type also significantly affected the response. TG formulations produced an $\sim 1$ percentage point greater increase in the O3I for the same EPA + DHA dose than an EE formulation. Some (18, 19), but not all (31, 39, 40) studies have reported increased bioavailability of LC n3 FA in the TG compared with EE form. There also appears to be a "food effect" for EPA + DHA (i.e., poorer absorption in the absence of a fatty meal), which is considerably more pronounced for the EE form than the TG $(22,23)$. Hence, a lower response to EE compared with TG forms on the O3I might be partly explained by this factor. Current evidence does not support a major effect of FA desaturase gene variants on the

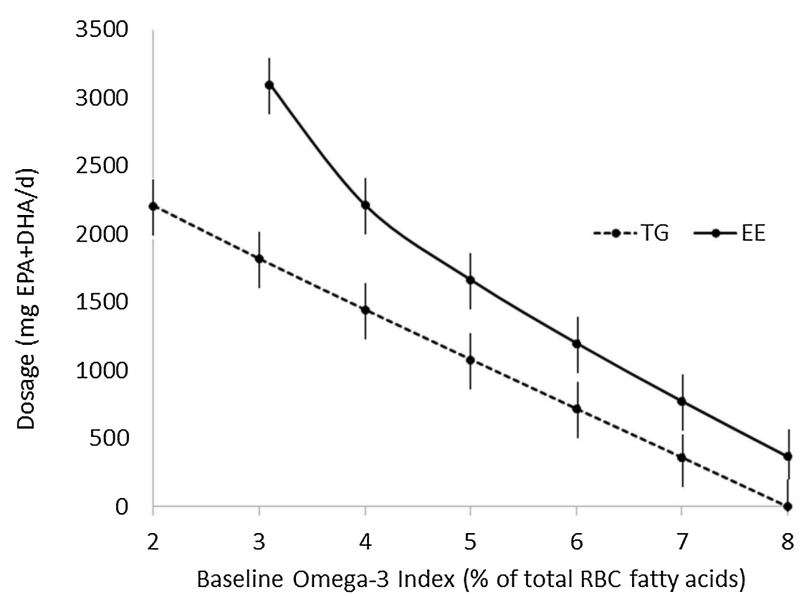

FIGURE 1 LC n-3 fatty acid doses needed to attain an RBC EPA + DHA concentration (omega-3 index, or $\mathrm{O} 3 \mathrm{I}$ in the equations) of $8 \%$ in $\sim 13 \mathrm{wk}$, as a function of the baseline O3I. The model equations as estimated using the 10fold cross-validation approach described in the article with an $n$ of 1422 were rearranged to solve for the necessary dosage to attain a postsupplementation O3I of $8 \%$. The results are shown with separate lines for ethyl ester (EE) and triglyceride (TG) supplements. The error bars reflect the 95\% CIs. The equation for TG is: Dose $=3292.68293-$

$\frac{\sqrt{7.29 \times 10^{-6}+1.64 \times 10^{-6}(-4.479+0.158 \text { BaselineO } 3 I+0.05 \text { Baseline O3I })}}{8.2 \times 10^{-7}}$.

The equation for EE is: Dose $=3292.68293-$

$\frac{\sqrt{7.29 \times 10^{-6}+1.64 \times 10^{-6}\left(-5.4+0.158 \text { BaselineO } 3 I+0.05 \text { Baseline } O 3 I^{2}\right)}}{8.2 \times 10^{-7}}$. 


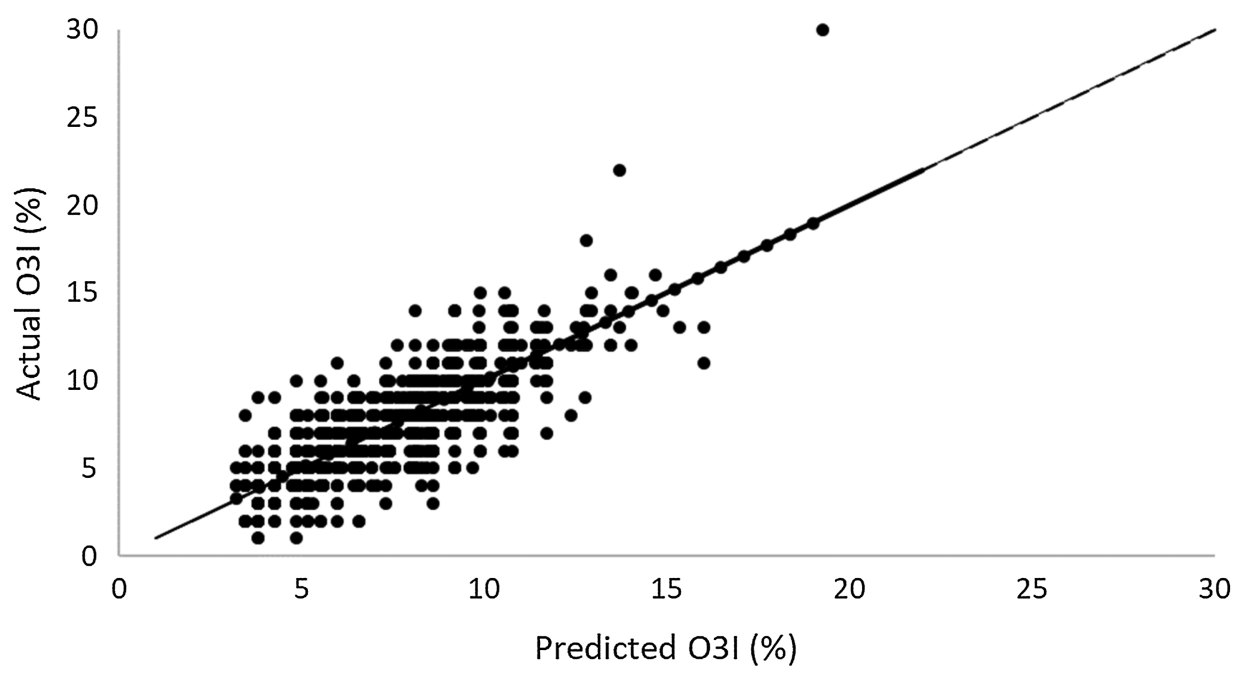

FIGURE 2 Predicted compared with observed RBC EPA + DHA concentration [omega-3 index (O3I)]. We used the model to calculate the predicted final O3I, which was then compared with the observed O3I values (see equation at end of paragraph). When using the model for the entire data set ( $n=1422$ ), observed values correlated with predicted values, with an $R^{2}$ of 0.69 . Two lines are shown: the line y $=\mathrm{x}$ (thin dashed line) illustrates the line of "perfect prediction," and the heavy solid line represents the best-fit line of the predicted compared with observed O3I values (Actual O3I $=0.063+0.993 *$ Predicted O3I). In the equation for the best-fit line, the intercept $(0.063 ; \mathrm{SE}=0.13)$ is not significantly different from $0(t$ test $P=0.62)$, and the slope $(0.993 ; \mathrm{SE}=0.04)$ is not significantly different from $1(t$ test $P=0.69)$. The predicted O3I $=$ baseline O3I + the predicted change in O3I, which is: $2.60+0.921 \times 1$ [if triglyceride supplements were used; otherwise, $\times 0$ ] $-0.842 \times$ baseline O3I [entered as an integer, not a fraction or percentage] $+0.05 \times(\text { baseline O3I })^{2}+0.0027 \times$ dose $\left[\mathrm{mg}\right.$ EPA + DHA/d] $-0.000000471 \times$ dose $^{2}$.

RBC FA response to n-3 FA supplementation (41). Surprisingly, duration of supplementation did not enter the final model. This probably reflects the fact that a majority of the changes in the O3I occurred within 13-14 wk, which was the average duration in this set of studies. This does not mean, however, that a new steady state was established, since that takes somewhat longer to achieve $(42,43)$.

\section{Potential research uses of the model}

The model equation developed herein can be used to estimate the final O3I (and 95\% CI) of a population given the LC n-3 FA dose and baseline O3I. As an example, a population with a baseline O3I of 4.9\% (like this pooled cohort) that is given $840 \mathrm{mg}$ EPA + DHA/d (e.g., $1 \mathrm{n}-3$ acid ethyl ester capsule) would achieve a mean O3I of $\sim 6.5 \%$ (95\% CI: $6.3 \%, 6.7 \%$ ). Rearranging the equation, one can calculate the approximate $\mathrm{EPA}+$ DHA doses (TG forms) to achieve a mean O3I of $8 \%$ in 13 wk: $2200 \mathrm{mg} / \mathrm{d}$ for a baseline O3I of $2 \%, 1500 \mathrm{mg}$ for a $4 \%$ baseline, and $750 \mathrm{mg}$ for a $6 \%$ baseline (Figure 1). Using this example, we predict that the minimum dose (i.e., the lower bound of a $95 \%$ CI for the mean required dose) of EPA + DHA necessary to be $95 \%$ certain that the mean baseline O3I of $4 \%$ will increase to $8 \%$ (in $13 \mathrm{wk}$ ) is $\sim 1750 \mathrm{~g} / \mathrm{d}$ of TG or $2500 \mathrm{~g} / \mathrm{d}$ of EE. The daily dose needed over a lifetime to achieve an O3I of $8 \%$ is likely much lower. For example, the average EPA + DHA intake in Japan is "only" $800-1000 \mathrm{mg} / \mathrm{d}$, and the mean O3I in the Japanese is $>8 \%$ (44).

A dose of about $2000 \mathrm{mg} / \mathrm{d}$ of EPA + DHA is much higher than current recommended intakes to reduce CVD risk. The 2015-2020 Dietary Guidelines for Americans recommend 8 oz of fish per week, which is said to be equivalent to about 250 mg/d EPA + DHA (45), and the American Heart Association recommends 1-2 servings of "oily" fish per week (assumed to approximate $500 \mathrm{mg} / \mathrm{d}$ EPA + DHA) to reduce CVD risk $(46,47)$. Using the model and assuming the TG form, these EPA + DHA intakes would increase the O3I from $4 \%$ to $\sim 6 \%$. According to National Health and Nutrition Examination Survey 20032008 data, $90 \%$ of Americans do not meet the 500-mg/d intake recommended by the Academy of Nutrition and Dietetics (48), and $80 \%$ do not meet the $250-\mathrm{mg} / \mathrm{d}$ goal (46).

Several large randomized controlled trials (RCTs) of n-3 FAs and CVD completed over the past decade have reported no effects, and these have been summarized multiple times in metaanalyses $(2,49)$. Only one of those trials directly measured the O3I and only in a subset of subjects. In that study, the average O3I increased from $4.8 \%$ to $6.7 \%$ after 3 mo. Only $23 \%$ of the treated patients reached an $\mathrm{O} 3 \mathrm{I}>8 \%$ (34). The model developed herein predicted a final value of $6.5 \%$ for that study population.

In 2018, the highest-dose RCT of LC n-3 FAs with clinical endpoints was reported. Bhatt et al. (50) used $4000 \mathrm{mg} / \mathrm{d}$ icosapent ethyl (EPA EE) in a cohort of $>8000$ statin-treated patients with hypertriglyceridemia. Major CVD events were reduced by $25 \%$. Effects on the O3I were not reported in this study, and the equation derived here cannot be used to estimate the effects on the O3I because only EPA was provided. Pure EPA, while raising RBC EPA, also slightly lowers RBC DHA concentrations (51), so the net effect on the O3I is difficult to predict.

\section{Strengths and limitations}

A strength of the current study is that it included many diverse data sets, which increases the generalizability of the model since the studies included a variety of ages, dosages, chemical formulations, and study durations in both healthy and diseased 
populations in 3 Western countries (United States, Italy, and Norway). Interstudy variability was minimized by use of the same laboratory method for the O3I. However, this analysis has several limitations and potential confounders, as well. For example, only one study directly (31) compared EE with TG LC n-3 FA forms, so the magnitude of the differences in the O3I response to these two forms should be considered tentative. Most studies used only one dosage compared with placebo, with only four studies (14, $31,35,36)$ investigating multiple doses. In addition, most of the cohorts were not racially diverse, with over $90 \%$ of subjects being white, likely explaining why race did not enter the final models. It is unknown how racial differences may affect the O3I response to dose. Similarly, because $74 \%$ of this aggregated cohort was male, the results may apply more robustly to men than women. Also, due to limitations in the range of baseline O3Is in these studies, the model works best for baseline values between $\sim 2 \%$ and $6 \%$. Hence, the predicted values are not as accurate for individuals who are already close to the target O3I of $8 \%$. This exercise also does not address the question of how much $\mathrm{EPA}+$ DHA should be taken to maintain an O3I of $8 \%$ once it is achieved. As noted earlier, the mean duration of treatment was only $13.6 \mathrm{wk}$, and steady-state levels were probably not achieved. The ratio of EPA to DHA in a given supplement could affect RBC membrane incorporation of the sum (52), but the narrow range of EPA/DHA ratios of the supplements used in these studies caused this variable to not enter the final model. Finally, no studies using krill oil (LC n-3 FA present mostly in phospholipid forms) were available. A myriad of other possible factors also could influence absorption and membrane incorporation of LC n-3 FAs that were not considered in this analysis, including fasted or fed state, the amount of fat taken with the supplement, possible drug interactions, physical activity, other background dietary factors (e.g., alcohol intake), physiological state (e.g., pregnancy, lactation), genetic differences, and dyslipidemia.

\section{Conclusions}

In order for $95 \%$ of subjects (not just 50\%) to achieve a desirable O3I from a baseline of $\sim 4 \%$, roughly $2000 \mathrm{~g} / \mathrm{d}$ EPA + DHA (depending on the chemical form) would likely be required. As noted, the equation developed here can aid in predicting population O3I changes, but because of the large interindividual variability in the O3I response to EPA + DHA supplementation, it will likely be less useful in the clinical setting where direct testing of the O3I would be the preferred approach to assessing EPA + DHA status.

The authors' responsibilities were as follows-REW and KHJ: cowrote the first draft; REW, GCS, AB, and NLT: performed statistical modeling; WSH and NLT: extensively edited the manuscript; all other authors (who were the original authors of the studies included in the analysis) provided input on the final version; and all authors: approved the final manuscript. WSH is the founder and president of OmegaQuant Analytics, LLC, a commercial laboratory providing fatty acid analytical services for researchers, health care providers, and consumers. KHJ is an employee of and NLT is a biostatistical consultant for OmegaQuant. GCS has received honoraria from Amarin Corp. PMKE and WSH are members of the Scientific \& Nutrition Advisory Council of the Seafood Nutrition Partnership. AB is an employee of the Global Organization for EPA and DHA Omega-3 s (GOED), a 501(c)6 not-for-profit trade association. None of the other authors have any conflicts to declare.

\section{References}

1. Siscovick DS, Barringer TA, Fretts AM, Wu JH, Lichtenstein AH, Costello RB, Kris-Etherton PM, Jacobson TA, Engler MB, Alger HM, et al. Omega-3 polyunsaturated fatty acid (fish oil) supplementation and the prevention of clinical cardiovascular disease: a science advisory from the American Heart Association. Circulation 2017;135(15): e867-84.

2. Abdelhamid AS, Brown TJ, Brainard JS, Biswas P, Thorpe GC, Moore HJ, Deane KH, AlAbdulghafoor FK, Summerbell CD, Worthington $\mathrm{HV}$, et al. Omega-3 fatty acids for the primary and secondary prevention of cardiovascular disease. Cochrane Database Syst Rev 2018;7:CD003177.

3. Bowman L, Mafham M, Wallendszus K, Stevens W, Buck G, Barton J, Murphy K, Aung T, Haynes R, Cox J, et al. Effects of n-3 fatty acid supplements in diabetes mellitus. N Engl J Med 2018;379(16): 1540-50.

4. Manson JE, Cook NR, Lee IM, Christen W, Bassuk SS, Mora S, Gibson $\mathrm{H}$, Albert CM, Gordon D, Copeland T, et al. Marine n-3 fatty acids and prevention of cardiovascular disease and cancer. N Engl J Med 2019;380:23-32.

5. Bhatt DL, Steg PG, Miller M, Brinton EA, Jacobson TA, Ketchum SB, Doyle RT Jr, Juliano RA, Jiao L, Granowitz C, et al. Effects of icosapent ethyl on total ischemic events: from REDUCE-IT. J Am Coll Cardiol 2019;73(22):2791-802.

6. Harris WS, von Schacky C. The Omega-3 Index: a new risk factor for death from coronary heart disease? Prev Med 2004;39:212-20.

7. Harris WS, Sands SA, Windsor SL, Ali HA, Stevens TL, Magalski A, Porter CB, Borkon AM. Omega-3 fatty acids in cardiac biopsies from heart transplant patients: correlation with erythrocytes and response to supplementation. Circulation 2004;110:1645-9.

8. Andersen LF, Solvoll K, Drevon CA. Very-long-chain n-3 fatty acids as biomarkers for intake of fish and n-3 fatty acid concentrates. Am J Clin Nutr 1996;64:305-11.

9. von Schacky C. The Omega-3 Index as a risk factor for cardiovascular diseases. Prostaglandins Other Lipid Mediat 2011;96(1-4):94-8.

10. Harris WS. The omega-3 index: clinical utility for therapeutic intervention. Curr Cardiol Rep 2010;12:503-8.

11. Harris WS, Del Gobbo L, Tintle NL. The Omega-3 Index and relative risk for coronary heart disease mortality: estimation from 10 cohort studies. Atherosclerosis 2017;262:51-4.

12. Baghai TC, Varallo-Bedarida G, Born C, Hafner S, Schule C, Eser D, Rupprecht R, Bondy B, von Schacky C. Major depressive disorder is associated with cardiovascular risk factors and low omega-3 index. J Clin Psychiatry 2010;72:1242-7.

13. Fontes JD, Rahman F, Lacey S, Larson MG, Vasan RS, Benjamin EJ, Harris WS, Robins SJ. Red blood cell fatty acids and biomarkers of inflammation: a cross-sectional study in a community-based cohort. Atherosclerosis 2015;240(2):431-6.

14. Flock MR, Skulas-Ray AC, Harris WS, Etherton TD, Fleming JA, KrisEtherton PM. Determinants of erythrocyte omega-3 fatty acid content in response to fish oil supplementation: a dose-response randomized controlled trial. J Am Heart Assoc 2013;2(6):e000513.

15. Keenan AH, Pedersen TL, Fillaus K, Larson MK, Shearer GC, Newman JW. Basal omega-3 fatty acid status affects fatty acid and oxylipin responses to high-dose n3-HUFA in healthy volunteers. J Lipid Res 2012;53(8):1662-9.

16. Sarter B, Kelsey KS, Schwartz TA, Harris WS. Blood docosahexaenoic acid and eicosapentaenoic acid in vegans: associations with age and gender and effects of an algal-derived omega-3 fatty acid supplement. Clin Nutr 2015;34:212-18.

17. Nosova EV, Chong KC, Alley HF, Harris WS, Boscardin WJ, Conte MS, Owens CD, Grenon SM. Clinical correlates of red blood cell omega-3 fatty acid content in male veterans with peripheral arterial disease. J Vasc Surg 2014;60(5):1325-31.

18. Neubronner J, Schuchardt JP, Kressel G, Merkel M, von Schacky C, Hahn A. Enhanced increase of omega-3 index in response to longterm n-3 fatty acid supplementation from triacylglycerides versus ethyl esters. Eur J Clin Nutr 2010;65:247-54.

19. Dyerberg J, Madsen P, Moller JM, Aardestrup I, Schmidt EB. Bioavailability of marine n-3 fatty acid formulations. Prostaglandins Leukot Essent Fatty Acids 2010;83:137-41.

20. Tintle NL, Pottala JV, Lacey S, Ramachandran V, Westra J, Rogers A, Clark J, Olthoff B, Larson M, Harris W, et al. A genome-wide association study of saturated, mono- and polyunsaturated red blood cell 
fatty acids in the Framingham Heart Offspring Study. Prostaglandins Leukot Essent Fatty Acids 2015;94:65-72.

21. Harris WS, Pottala JV, Lacey SM, Vasan RS, Larson MG, Robins SJ. Clinical correlates and heritability of erythrocyte eicosapentaenoic and docosahexaenoic acid content in the Framingham Heart Study. Atherosclerosis 2012;225:425-31.

22. Lawson LD, Hughes BG. Absorption of eicosapentaenoic acid and docosahexaenoic acid from fish oil triacylglycerols or fish oil ethyl esters co-ingested with a high-fat meal. Biochem Biophys Res Comm 1988;156:960-3.

23. Davidson MH, Johnson J, Rooney MW, Kyle ML, Kling DF. A novel omega-3 free fatty acid formulation has dramatically improved bioavailability during a low-fat diet compared with omega3-acid ethyl esters: the ECLIPSE (Epanova compared to Lovaza in a pharmacokinetic single-dose evaluation) study. J Clin Lipidol 2012;6:573-84.

24. West AA, Yan J, Jiang X, Perry CA, Innis SM, Caudill MA. Choline intake influences phosphatidylcholine DHA enrichment in nonpregnant women but not in pregnant women in the third trimester. Am J Clin Nutr 2013;97(4):718-27.

25. Shearer GC, Pottala JV, Hansen SN, Brandenburg V, Harris WS. Effects of prescription niacin and omega-3 fatty acids on lipids and vascular function in metabolic syndrome: a randomized controlled trial. J Lipid Res 2012;53(11):2429-35.

26. Carney RM, Freedland KE, Rubin EH, Rich MW, Steinmeyer BC, Harris WS. Omega-3 augmentation of sertraline in treatment of depression in patients with coronary heart disease: a randomized controlled trial. JAMA 2009;302:1651-7.

27. Larson MK, Ashmore JH, Harris KA, Vogelaar JL, Pottala JV, Sprehe M, Harris WS. Effects of omega-3 acid ethyl esters and aspirin, alone and in combination, on platelet function in healthy subjects. Thromb Haemost 2008;100:634-41.

28. Grenon SM, Owens CD, Nosova EV, Hughes-Fulford M, Alley HF, Chong K, Perez S, Yen PK, Boscardin J, Hellmann J, et al. Shortterm, high-dose fish oil supplementation increases the production of omega-3 fatty acid-derived mediators in patients with peripheral artery disease (the OMEGA-PAD I Trial). J Am Heart Assoc 2015;4(8): e002034.

29. Newman JW, Pedersen TL, Brandenburg VR, Harris WS, Shearer GC. Effect of omega-3 fatty acid ethyl esters on the oxylipin composition of lipoproteins in hypertriglyceridemic, statin-treated subjects. PLoS One 2014;9(11):e111471.

30. Heydari B, Abdullah S, Pottala JV, Shah R, Abbasi S, Mandry D, Francis SA, Lumish H, Ghoshhajra BB, Hoffmann U, et al. Effect of omega-3 acid ethyl esters on left ventricular remodeling after acute myocardial infarction clinical perspective: the OMEGA-REMODEL randomized clinical trial. Circulation 2016;134(5):378-91.

31. Hedengran A, Szecsi PB, Dyerberg J, Harris WS, Stender S. n-3 PUFA esterified to glycerol or as ethyl esters reduce non-fasting plasma triacylglycerol in subjects with hypertriglyceridemia: a randomized trial. Lipids 2015;50(2):165-75.

32. Harris WS, Pottala JV, Sands SA, Jones PG. Comparison of the effects of fish and fish-oil capsules on the $\mathrm{n} 3$ fatty acid content of blood cells and plasma phospholipids. Am J Clin Nutr 2007;86:1621-5.

33. Gidding SS, Prospero C, Hossain J, Zappalla F, Balagopal PB, Falkner B, Kwiterovich P. A double-blind randomized trial of fish oil to lower triglycerides and improve cardiometabolic risk in adolescents. J Pediatr 2014;165(3):497-503.e2.

34. Harris WS, Masson S, Barlera S, Milani V, Pileggi S, Franzosi MG, Marchioli R, Tognoni G, Tavazzi L, Latini R. Red blood cell oleic acid levels reflect olive oil intake while omega-3 levels reflect fish intake and the use of omega-3 acid ethyl esters: the Gruppo Italiano per lo Studio della Sopravvivenza nell'Infarto Miocardico-Heart Failure trial. Nutr Res 2016;36(9):989-94.

35. Dewell A, Marvasti FF, Harris WS, Tsao P, Gardner CD. Low- and high-dose plant and marine (n-3) fatty acids do not affect plasma inflammatory markers in adults with metabolic syndrome. J Nutr 2011;141(12):2166-71.
36. Skulas-Ray AC, Kris-Etherton PM, Harris WS, Vanden Heuvel JP, Wagner PR, West SG. Dose-response effects of omega-3 fatty acids on triglycerides, inflammation, and endothelial function in healthy persons with moderate hypertriglyceridemia. Am J Clin Nutr 2011;93: 243-52.

37. Skulas-Ray AC, Alaupovic P, Kris-Etherton PM, West SG. Doseresponse effects of marine omega-3 fatty acids on apolipoproteins, apolipoprotein-defined lipoprotein subclasses, and Lp-PLA2 in individuals with moderate hypertriglyceridemia. J Clin Lipidol 2015;9(3):360-7.

38. Raftery AE. Bayesian model selection in social research. Sociol Methods 1995;25:111-63.

39. Krokan HE, Bjerve KS, Mork E. The enteral bioavailability of eicosapentaenoic acid and docosahexaenoic acid is as good from ethyl esters as from glyceryl esters in spite of lower hydrolytic rates by pancreatic lipase in vitro. Biochim Biophys Acta 1993;1168(1): $59-67$.

40. Luley CW, Wieland HV, Grunwald J. Bioavailability of omega-3 fatty acids: ethyl ester preparations are as suitable as triglyceride preparations. Akt Ernaehr Med 1990;15:123-5.

41. Al-Hilal M, Alsaleh A, Maniou Z, Lewis FJ, Hall WL, Sanders TA, O'Dell SD. Genetic variation at the FADS1-FADS2 gene locus influences delta-5 desaturase activity and LC-PUFA proportions after fish oil supplement. J Lipid Res 2013;54(2): $542-51$.

42. Browning LM, Walker CG, Mander AP, West AL, Madden J, Gambell JM, Young S, Wang L, Jebb SA, Calder PC. Incorporation of eicosapentaenoic and docosahexaenoic acids into lipid pools when given as supplements providing doses equivalent to typical intakes of oily fish. Am J Clin Nutr 2012;96:748-58.

43. Katan MB, Deslypere JP, van Birgelen AP, Penders M, Zegwaard M. Kinetics of the incorporation of dietary fatty acids into serum cholesteryl esters, erythrocyte membranes, and adipose tissue: an 18month controlled study. J Lipid Res 1997;38:2012-22.

44. Itomura M, Fujioka S, Hamazaki K, Kobayashi K, Nagasawa T, Sawazaki S, Kirihara Y, Hamazaki T. Factors influencing EPA+DHA levels in red blood cells in Japan. In Vivo 2008;22(1):131-5.

45. US Department of Agriculture. Dietary Guidelines for Americans, 2010. [Internet]. Available from: https://health.gov/dietaryguidelines/2010/.

46. Richter CK, Bowen KJ, Mozaffarian D, Kris-Etherton PM, SkulasRay AC. Total long-chain n-3 fatty acid intake and food sources in the United States compared to recommended intakes: NHANES 2003 2008. Lipids 2017;52(11):917-27.

47. Rimm EB, Appel LJ, Chiuve SE, Djoussé L, Engler MB, Kris-Etherton PM, Mozaffarian D, Siscovick DS, Lichtenstein AH. Seafood longchain n-3 polyunsaturated fatty acids and cardiovascular disease: a science advisory from the American Heart Association. Circulation 2018;138(1):e35-47.

48. Vannice G, Rasmussen H. Position of the Academy of Nutrition and Dietetics: dietary fatty acids for healthy adults. J Acad Nutr Diet 2014;114(1):136-53

49. Maki KC, Palacios OM, Bell M, Toth PP. Use of supplemental longchain omega-3 fatty acids and risk for cardiac death: an updated meta-analysis and review of research gaps. J Clin Lipidol 2017;11(5): $1152-60$.

50. Bhatt DL, Steg PG, Miller M, Brinton EA, Jacobson TA, Ketchum SB, Doyle RT Jr, Juliano RA, Jiao L, Granowitz C, et al. Cardiovascular risk reduction with icosapent ethyl for hypertriglyceridemia. N Engl J Med 2019;380(1):11-22.

51. Allaire J, Harris WS, Vors C, Charest A, Marin J, Jackson KH, Tchernof A, Couture P, Lamarche B. Supplementation with high-dose docosahexaenoic acid increases the Omega-3 Index more than highdose eicosapentaenoic acid. Prostaglandins Leukot Essent Fatty Acids 2017;120:8-14

52. Cao J, Schwichtenberg KA, Hanson NQ, Tsai MY. Incorporation and clearance of omega-3 fatty acids in erythrocyte membranes and plasma phospholipids. Clin Chem 2006;52:2265-72. 